\title{
Analysis on Key Points of Foreign Trade English Correspondence
}

\section{Translation}

\author{
Suping Jiang ${ }^{1}$,BiqingLi ${ }^{2}$, ${ }^{*}$, Zhao $\mathrm{Li}^{3}$ \\ ${ }^{1}$ Guangxi Talent International College, Qinzhou Guangxi 535000, China; \\ ${ }^{2}$ College of Mechanical and Electronic Engineering, Hezhou university, Hezhou Guangxi 542899, \\ China; \\ ${ }^{3}$ Management EngineeringDepartment, \\ Guangxi vocational andtechnicalcollege ofcommunications,Liuzhou Guangxi 530000, China; \\ janliful@163.com
}

\begin{abstract}
Modern economic development shows that: international trade activity is a significant component of world economic development, and turns into strong impetus for world economic development. Foreign trade business grows rapidly, which is a huge shock to the global economy. Many scholars and translators are devoted to translation and research wave of foreign trade English correspondence. Foreign trade English correspondence is a kind of indispensable communication mode of foreign trade activities. In order to improve the quality of foreign trade English correspondence translation, translators should find out and grasp numerous common sense of economy and trade; translators can comprehend the special meanings of general terms correctly in various kinds of situational contexts of commercial affairs. Translators should try their best to master terms, fixed sentence patterns as well as special words and sentence patterns of English for trade. Moreover, translators should improve their own language accomplishments and enhance the sensitivity of language; translators should conduct accurate translations and achieve the equivalent transformation of information on the premise of grasping foreign trade English correspondence precisely and appropriately.
\end{abstract}

Keywords: foreign trade English correspondence;key points of translations;analysis

\section{Introduction}

English becomes one of the most important languages of connecting with other countries, because the trend of international economic integration strengthens; the use of foreign trade English correspondence for connecting with foreign commercial businesses also appears to be particularly important. Translators should have good commands of the use of foreign trade English correspondence, accurately grasp the main contents which need to be expressed, and tell the other people involved, which not only makes for the smooth development of commercial trade process, but also improves the success rate of the transaction. That is conducive to improve the foreign trade image of the enterprise. As such, we need to know more about foreign trade correspondence, and use foreign trade correspondence with ease. Taking foreign trade English correspondence as an example, this paper focuses on the laws and features of words in foreign trade English correspondence. Based on the translation norms 
of foreign trade correspondence, this paper analyzes the key points of foreign trade correspondence translation.

\section{Features of Foreign Trade English Correspondence}

(1) Lexicon Features of Foreign Trade English Correspondence

Firstly, trade terms are used frequently; secondly, acronyms are used. The use of acronyms can effectively improve the work efficiency of translators. Thirdly, translators should pay special attention to grasping the specific professional connotations of common words which are formed by extension, conversion, and addition in foreign trade correspondence, avoiding being confused with general terms.

Besides, translators must convey the concept of quantity accurately, since such data as quantity, amount of money, time, price, and specification in trade and business have immeasurable effects. In this connection, the words which express the concept of time must be strictly differentiated.

(2)Features of Foreign Trade English Correspondence Writings

The following stylistic features are formed in the structure and organization of business correspondence.

The first one is simple and concise, as well as rigorous and precise. The rapidly-developing information era attaches great importance to timeliness; foreign trade activity is no exception. Therefore, more simple sentences, short compound sentences, short complex sentences and elliptical sentences should be applied in foreign business correspondence, in order to facilitate mutual understandings and communications.

Foreign business correspondence includes relatively broad contents. For instance, the rights, responsibilities and obligations of the both parties of the transaction are important components of foreign trade contracts. As such, the accuracy and preciseness of translation contents should be emphasized in particular while foreign business correspondence is translated. In addition, the information content of business correspondence is extensive. A professional translator should use simple words; ambiguous words should be avoided by all means; the mistakes in comprehension of opposite side should be avoided. Unnecessary conflicts should be reduced.

The second one is popular and easy to understand. The function that foreign business correspondence places particular emphasis on is to convey information on commercial affairs; it is the link of transaction relations. Plain and simple language can make people have immediate rapport, which can facilitate transaction behaviors.

The third one is documentary and accurate. When translating foreign business correspondence, translators should avoid to use uncommon words and try their best to employ common words, in that foreign business correspondence also attaches great importance to the efficient transmission of information while emphasizing the on-the-spot record and accuracy of information transmission. Translators should lay emphasis on euphemistic expressions and gentle tone. Besides, the writing style should conform to the seven principles which are accuracy, clarity, concision, politeness, completion, concreteness and consideration. 


\section{Norms of Foreign Trade English Correspondence Translation}

Compared with original translations, the differences lie in the following facts: translation of foreign business correspondence requires more vocabularies; words need to be more accurate; the requirements of overall accuracy rate are stricter. As such, "faithfulness and smoothness" become the fundamental principles for using foreign trade English correspondence. The so-called "faithfulness" is to express information directly and clearly without any modification, which is popular and easy to understand. The "smoothness" requires the smooth sentences and popular words; the use of punctuation marks and emotional colors should be paid attention; the efficiency of business communication should be improved. In short, the translation norms of foreign business correspondence can summarized in six characters which are namely "faithfulness, accuracy, and unification".

(1)The original texts should be respected and the expressions should be accurate. The "faithfulness" in foreign trade English correspondence refers to the equivalence between expression contents and information in original texts. Translators should conduct translation work on the basis of respecting the original texts instead of changing the information in the original contexts without permission. The core requirement of foreign trade English correspondence translation is accurate expression. Launches of international trades tend to involve price, conditions, payment methods, claims and other issues. These issues seem to be trivial matters; disputes may sometimes arise from a radix point or a word. As a result, in the process of transforming information, issues on concepts must be expressed precisely. For example, quantity, unit and amount of money need to be expressed correctly. The accuracy of trade terminologies should be improved.

(2)Translations should be smooth and expressive, as well as clear and easy to understand, which requires translators to use sentences and corpus appropriately. Furthermore, the language can not be used across the industry. The words should be accurate and easy to understand, and the words should used flexibly. The writing forms of translations should keep consistent with the original texts on the premise of being faithful to the original texts. Meanwhile, the translated contents must accord with the expression ways and customs of Chinese, and the contents should be popular and easy to understand.

(3)Translations should be authentic and normative; translated terms should be unified. The translation of foreign trade English correspondence should be stipulated and conform to conventional implications. "Authenticity and norm" requires the words and writing styles to conform to the linguistic norms and writing norms of business documents. The "unification of translated terms" here indicates that some concepts which are used should take notice of the principle of maintaining consistency with information in original texts. The circumstance that the same concept uses many meanings in translation should be avoided.

In conclusion, foreign trade English correspondence translation should comply with the norms of " respecting original texts", "being smooth and expressive" and "unifying translated terms". In order to ensure the unification of translated terms, translators can retrieve relevant business documents and dictionaries, avoiding to making mistakes in translating the commonly-used trade terms and organization names in the field of business English. 


\section{Requirements on Foreign Trade English Correspondence Translation}

Based on the particularities of foreign trade English correspondence translation, the following requirements or notices on translation are proposed for foreign trade English correspondence translation.

(1)Translators should employ terminologies and fixed sentence patterns for translation. The particularities of foreign trade English correspondence require translators to grasp terminologies, writing formats and styles, and expression methods in correspondence as many as possible. Translator should use correct translation methods to make the translation contents accurate, so as to satisfy the needs of foreign trade English correspondence, on account of the fact that the usage frequency of terminologies is found to be high than any other practical writings after investigations.

(2)Before using terminologies, translators should clearly know the professional meanings of the terminologies and indiscriminately use the usage specifications of terminologies, making sure the standardization and rationalization of language of translated texts. Translators should master fixed sentence patterns, which can improve the efficiency of foreign trade work and standardize the contents of business letters. In terms of translation of the international business field, translators should grasp the idiomatic usage. Translators should translate based on the Chinese expression customs, enabling readers to obtain the same information and feelings with the original texts while reading the translated texts.

(3)Translators should determine the use of words for translation according to the expressed emotions in the original texts. Language culture is rich and colorful, and the language used in different situations can have many kinds of meanings. In foreign trade English correspondence, many common words, and sentences in different situational contexts may be endowed with new implications; they are likely to further become certain terminologies in the future. In this case, translators should update knowledge on foreign trade and business at any time and know the extended meanings of certain words, flexibly responding to the language used in different situations.

(4)The original texts should be respected, and the words for translation should be used accurately. The main purpose of using foreign trade English correspondence is to transmit information for both sides. There is no need for any modification, and what is required is simple language. Translators don't need to make more changes in translation; translators only need to make translations based on the structures of the original texts.

(5)The information in the original texts should be translated accurately, and mistakes should be avoided. The translation of foreign trade English correspondence attaches great importance to accuracy, and it requires no modification of the translated texts. Simultaneously, in order to avoid the errors in expression, translators can use "mirror-style" and one-to-one mode to make translations, reducing the error rate to zero.

Apart from the above-mentioned, in terms of the obvious differences between different countries and regions due to culture, the translated contents should be cautious and serious instead of ambiguous and sardonic. In terms of correspondence, translators shall not change the information in the original texts arbitrarily. If mistakes appear in translations, vital problems will be caused; corresponding legal responsibility will be involved in serious cases. In a word, in order to improve the efficiency of foreign trade English translation and master the common terminologies and usage skills in foreign trade business accurately, translators 
can learn from the writing structures and translation norms of foreign trade English correspondence at home and abroad. Translators should combine the domestic realities and master various kinds of formats and structures, writing features and terminologies of business correspondence in foreign trade business activities through a large number of cases and living examples. Translators should use the above-mentioned flexibly.

\section{Conclusion}

This paper makes a brief analysis of notices of foreign trade English correspondence translation by the laws and features of words in foreign trade English correspondence, according to the three norms of foreign trade English correspondence translation. In summary, the general principle of foreign trade English correspondence translation is that the target language must conform the translation standard of "being faithful to the original texts" and "smoothness". Moreover, in the process of foreign business correspondence translation, translators should cultivate the consciousnesses of being flexible and constantly improve their own English and Chinese language accomplishments. According to the contexts and speeds of the original texts, translators should use translation skills flexibly, making sentence expression smooth and natural. Translators should respect the original texts and not be restricted to original texts, striving to maintain the unique language and writing styles of business correspondence while making the translated texts more standard and authentic. Furthermore, the equivalent transformation of information can be achieved.

\section{Acknowledgement}

This work is supported the following fund :

2016 The project of improving the basic ability of young teachers in Colleges and universities in Guangxi:"An empirical study of Guangxi Beibu Gulf Economic Zone Foreign Trade Company foreign trade English correspondence"(No,KY2016YB886).

2015 college students' innovative training program: "Research on the application of value added travel experience in the mobile terminal of the 'ethnic custom travel' in Guangxi" (No 201511838070);\&\&"The design and development HeYuanTong Campus Mobile Phone APP based on Android" (No 201511838034).

2015 Teaching case project construction project of hezhou university: "Tourist positioning and guiding system project of Huangyao scenic";\&\&"Development and application of the information management system of 'Huang Yao Tong"'.

Project of scientific research and technology development project of Hezhou: "Design and implementation of agricultural products e-commerce platform based on Semantic Technology" (No,Hekeneng 1506006)

Scientific research project of hezhou university:"Research and development of E-government platform based on mobile terminal" (No 2015ZZZK03);

Reform in Education project of hezhou university: "Internet of things"(No hzxytszy201501);\&\&"Research on application personnel training model of Communications for SMEs"(No hzxyjg201525);

Master degree discipline construction scientific research and Cultivation Project: "Research on the social work service of the teenagers' Network Addiction"(No 
2015SHGZ005) \&\&"Research on the intelligent development of rural tourism in Guangxi based on the Internet of things" (No 2015MTA16);

\section{Reference}

[1] Tom,Discourse and Process [M]. London: Longman Group Ltd, 2010.

[2] Pinto, D. Genre Analysis of Business Letters of Negotiation [J]. English for Specific Purposes, 2012(2).

[3] Bhatia, V. Analyzing Genre: Language Use in Professional Settings [M]. London: Longman,2003.

[4] Nunan, D. S. Theory Applications and Limitations[M]. London: Penguin Group, 2003.

[5]Nida,E.A.DiscourseandTheTranslator[M].Shanghai:ShanghaiForeign Language Education Press, 2011.

[6] Beaugrande, H. English for Specific Purposes[M]. Cambridge University Press, 2015.

[7] Hatim, B.Language, Culture, and Translation[M]. Shanghai: Shanghai Foreign Language Education Press,2013. 